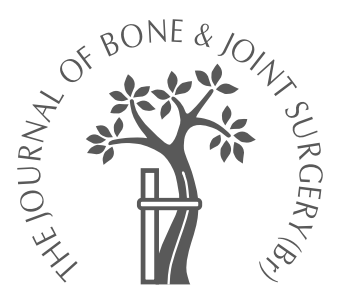
N. P. Walton,
C. Darrah,
L. Shepstone,
S. T. Donell,
H. Phillips

From the Norfolk o Norwich University Hospital, Norwich, and Institute of Health, University of East Anglia, England

N. P. Walton, FRCS (Trauma \& Orth), Specialist Registrar in Orthopaedics C. Darrah, RGN, Clinical Research Co-ordinator L. Shepstone, PhD, Statistician

S. T. Donell, MD, Honorary Reader

H. Phillips, FRCS,

Consultant Orthopaedic

Surgeon

Institute of Orthopaedics,

Norfolk \& Norwich

University Hospital, Colney

Lane, Norwich NR4 7UY, UK.

Correspondence should be sent to Mr N. P. Walton;

e-mail:

neil@nwalton22.fsnet.co.uk

(C)2005 British Editorial

Society of Bone and

Joint Surgery

doi:10.1302/0301-620X.87B4.

$15917 \$ 2.00$

$J$ Bone Joint Surg [Br]

2005;87-B:458-62.

Received 17 August 2004;

Accepted after revision

22 October 2004

\title{
The Elite Plus total hip arthroplasty
}

\author{
THE NEED FOR RADIOLOGICAL SURVEILLANCE
}

We prospectively studied 217 patients who underwent 234 Elite Plus total hip

arthroplasties. At a mean of 6.4 (SD 0.7 ) years post-operatively, 39 patients had died and 22 were either lost to follow-up or had no radiographs available. Clinical (Oxford hip score) and radiological assessments were performed on 156 patients (168 hip arthroplasties) who had a mean age of 67.7 (SD 9.7) years at operation.

In the assessed group, 26 of $159(16.4 \%)$ of femoral stems which had not already been revised and 19 of $159(11.9 \%)$ of acetabular cups were definitely loose. In total, 52 of 168 $(31 \%)$ of hips had either been revised or had definite evidence of loosening of a component. We could not establish any relationship between clinical and radiological outcomes.

Despite the fact that the clinical outcome and rate of revision for the Elite Plus appeared to meet international standards, our findings give us cause for concern. We believe that joint registries should include radiological surveillance in order to provide reliable information about medium-term outcomes for hip prostheses.

The Elite Plus total hip arthroplasty system (DePuy, Warsaw, Indiana), introduced in 1994, is the second modular evolution of the original Charnley low friction arthroplasty. It is a cemented prosthesis with a modular, stainlesssteel femoral stem and an ultra-high-molecular-weight polyethylene (UHMWPE) acetabular component. The standard head is also made from stainless steel (Ortron 90; DePuy).

To date, there have been no reports in the literature of standard metal-UHMWPE bearing Elite Plus components. The only study involving its stem reported catastrophic early failure when used with a zirconia ceramic head and a cross-linked UHMWPE (Hylamer) acetabular component. ${ }^{1}$

National hip registries have been established to assess the outcome of new and modified prostheses such as the Elite Plus. These registries often use revision and clinical information but rarely include radiological data.

We have, therefore, reviewed the mediumterm outcome of the Elite Plus and addressed the need for hip registries to include radiological surveillance if they are to provide accurate data on outcome.

\section{Patients and Methods}

All 217 patients, who were to undergo an Elite Plus total hip arthroplasty (THA) in one centre during 1995, were recruited prospectively into
Table I. Details of the 156 patients and 168 replacements for which the follow-up outcome was known

\begin{tabular}{lcc}
\hline & Patients & Replacements \\
\hline $\begin{array}{l}\text { Age at surgery in yrs } \\
\quad \text { Mean (SD) }\end{array}$ & $67.7(9.7)$ & $67.4(9.6)$ \\
$\begin{array}{l}\text { Time to follow-up in mths } \\
\quad \text { Mean (SD) }\end{array}$ & $6.4(0.7)$ & $6.3(0.7)$ \\
$\begin{array}{l}\text { Gender } \\
\quad \text { Men }\end{array}$ & 54 & 59 \\
$\quad$ Women & 102 & 109 \\
Side & & \\
$\quad$ Left & & 70 \\
$\quad$ Right & & 98 \\
\hline
\end{tabular}

a post-operative clinical and radiological surveillance programme. Review took place at a mean of 6.4 (SD 0.7) years after surgery. Data were gathered about the surgical teams involved, the grade of surgeon, the surgical approach and the type of cement used. Patients were reviewed clinically using the Oxford hip score. $^{2}$

Of the 217 patients (234 THAs), 39 had died before our follow-up review, ten were lost to follow-up and 12 had no follow-up radiographs available. Nine patients (nine THAs) had already been revised by the time of our review. There were 156 patients (168 THAs) available with the required follow-up data. At the time of our study, the nine patients who had undergone revision were still alive and being reviewed. Table I gives the details of 
patients and replacements when a follow-up outcome was known.

All the patients had a cemented Elite Plus THA with a 28 mm Ortron 90 head. Eighty-four THAs had been performed by one surgical team, 37 by another and 38 by five other teams. Ninety-two operations had been performed by consultants and 67 by specialist registrars. All but three procedures had been undertaken through an anterolateral approach.

Palacos R cement (Biomet Inc, Warsaw, Indiana) was used in 142 THAs, Palacos LV (Biomet Inc) in seven and a mixture of Palacos LV and Palacos $\mathrm{R}$ in ten. For these, the Palacos LV cement was placed distally in the femur and the standard (Palacos R) was placed proximally.

Radiological review involved taking plain anteroposterior radiographs of the pelvis immediately after surgery and five years later. The radiographs were taken in a standard manner, with patients lying supine with their anterior superior iliac spines equidistant from the table top, their femora internally rotated and their heels separated. The film and beam were centred $2.5 \mathrm{~cm}$ above the symphysis pubis with a focal film distance of $115 \mathrm{~cm}$ and the beam collimated to include the proximal femora. The radiographs were assessed by two independent observers (NPW, CD) using the criteria of Johnston et al. ${ }^{3}$ Agreement between observers was necessary for data to be included and, when disagreement occurred, a consensus view was obtained with the help of a third observer if necessary.

Radiological data were further assessed to determine whether prostheses were loose or at risk. The criteria used were: 1) those of Harris, McCarthy and O'Neill ${ }^{4}$ for definite loosening of the femoral stem as modified by Madey et $\mathrm{al}^{5}$ and Loudon and Charnley; ${ }^{6}$ 2) the refined criteria of Kobayashi et $\mathrm{al}^{7}$ for loosening of the femoral stem which defined the presence of a lytic lesion $(\geq 2 \mathrm{~mm}$ ) or migration of the stem ( $\geq 2 \mathrm{~mm}$ ) as predictors of failure; 3 ) those of Hodgkinson, Shelley and Wroblewski ${ }^{8}$ for definite acetabular loosening as modified by Mulroy and Harris; $\left.{ }^{9} 4\right)$ the criteria of Harris et al for definite loosening and/or Hodgkinson et al for definite acetabular loosening; ${ }^{4,6,8,9}$ and 5) the criteria of Harris et al and Hodgkinson et al for definite loosening plus any revisions for aseptic loosening. ${ }^{4,6,8,9}$

The survival of the prosthesis was calculated, with $95 \%$ confidence intervals (95\% CI) using these definitions.
Table II. Number of replacements with evidence of loosening at follow-up

\begin{tabular}{lll}
\hline Criteria used & Number of THAs & Percentage $(\mathbf{9 5} \% \mathbf{C l})$ \\
\hline Harris $^{4-6}$ & $26 / 159$ & $16.4(14.2$ to 18.5$)$ \\
Refined Kobayashi $^{7}$ & $29 / 159$ & $18.2(15.9$ to 20.6$)$ \\
${\text { Hodgkinson } \text { et }^{8}}^{8}$ & $19 / 159$ & $11.9(10.3$ to 13.6$)$ \\
Harris and/or Hodgkinson & $43 / 159$ & $27.0(23.9$ to 30.2$)$ \\
Revision or any loosening & $52 / 168$ & 31.0 (27.7 to 34.3$)$ \\
\hline
\end{tabular}

Statistical analysis. This was performed using Fisher's exact test for categorical data and a two-tailed $t$-test for continuous data. A p value of less than 0.05 was considered to be significant.

\section{Results}

Evaluation of the cementation on the immediate post-operative radiographs showed that $99.4 \%$ of THAs had a grading of A or B according to the criteria of Barrack, Mulroy and Harris ${ }^{10}$ and $0.6 \%$ of $\mathrm{C}$ or D. There was no leakage of cement below the cement restrictor in 117 (73.6\%) of cases but some leakage in $26.4 \%$. No deficiency of the femoral cement mantle was identified in 149 (94\%) of THAs, but there was some deficiency in the remainder. The position of the femoral stem was neutral in 111 (69.8\%) of THAs, while $30(18.9 \%)$ of stems were in $>4^{\circ}$ of varus and 18 $(11.3 \%)$ in $>4^{\circ}$ of valgus.

For the 168 THAs for which loosening data were available, 52 (31\%, 95\% CI 27.7 to 34.3$)$ showed either definite evidence of loosening of the component or had been revised for loosening of the component within six years (Table II).

There was not, however, any relationship between the incidence of loosening and either the age of the patients or their Oxford hip score. There was no significant relationship between clinical and radiological outcomes $(\mathrm{p}=0.884$, excluding revisions; Table III).

Some factors were significantly associated with loosening and/or revision. These were deficiency of the femoral cement mantle $(p=0.0075)$ and the type of bone cement used ( $\mathrm{p}=0.036$, using Harris's criteria; Table IV).

\section{Discussion}

Prostheses evolve in an attempt to optimise the outcome of joint replacement surgery, but inherent risks accompany these changes to a tried and tested implant. As experience

Table III. Relationship of age at surgery and Oxford hip score to signs of loosening

\begin{tabular}{lllll}
\hline & $\begin{array}{l}\text { Harris }^{4-6} \\
\text { score }\end{array}$ & $\begin{array}{l}\text { Hodgkinson } \\
\text { score }\end{array}$ & $\begin{array}{l}\text { Harris and/or } \\
\text { Hodgkinson score }\end{array}$ & $\begin{array}{l}\text { Revision or } \\
\text { any loosening }\end{array}$ \\
\hline Age at surgery in yrs & & & & \\
$\quad$ Mean (SD) with loosening & $68.1(9.9)$ & $67.5(8.1)$ & $67.7(9.2)$ & $68.1(9.9)$ \\
$\quad$ Mean (SD) without loosening & $67.3(9.4)$ & $67.4(9.7)$ & $67.3(9.6)$ & $67.3(9.4)$ \\
p value & 0.685 & 0.945 & 0.819 & 0.685 \\
Total Oxford hip score & & & & $20.9(9.8)$ \\
$\quad$ Mean (SD) with loosening & 20.9 & $19.9(12.4)$ & $23.0(11.1)$ & $23.7(10.8)$ \\
Mean (SD) without loosening & 23.7 & $21.0(10.4)$ & $23.3(10.6)$ & 0.246 \\
p value & 0.246 & 0.253 & 0.884 &
\end{tabular}


Table IV. Incidence of loosening using the different criteria

\begin{tabular}{|c|c|c|c|c|c|}
\hline & Number & Harris $^{4-6}(\%)$ & Hodgkinson $^{8}(\%)$ & $\begin{array}{l}\text { Harris and/or } \\
\text { Hodgkinson }(\%)\end{array}$ & $\begin{array}{l}\text { Revision or any } \\
\text { loosening }(\%)\end{array}$ \\
\hline \multicolumn{6}{|l|}{ Gender } \\
\hline Men & 116 & 17.5 & 14.0 & 29.8 & 32.2 \\
\hline Women & 43 & 15.7 & 10.8 & 25.5 & 30.2 \\
\hline $\mathrm{p}$ value & & 0.824 & 0.613 & 0.580 & 0.862 \\
\hline \multicolumn{6}{|l|}{ Side } \\
\hline Left & 116 & 9.5 & 9.5 & 19.1 & 27.1 \\
\hline Right & 43 & 20.8 & 13.5 & 32.3 & 33.7 \\
\hline$p$ value & & 0.078 & 0.618 & 0.071 & 0.401 \\
\hline \multicolumn{6}{|l|}{ Barrack grade ${ }^{10}$} \\
\hline$A$ or $B$ & 158 & 16.5 & 12.0 & 27.2 & 29.9 \\
\hline C or D & 1 & 0 & 0 & 0 & 66.7 \\
\hline$p$ value & & 1.0 & 1.0 & 1.0 & 0.221 \\
\hline \multicolumn{6}{|c|}{ Cement leakage below restrictor } \\
\hline Yes & 40 & 15.0 & 5.0 & 20.0 & 20.0 \\
\hline No & 117 & 17.1 & 14.5 & 29.9 & 32.2 \\
\hline$p$ value & & 1.0 & 0.160 & 0.305 & 0.164 \\
\hline \multicolumn{6}{|c|}{ Femoral cement mantle deficiency } \\
\hline Yes & 11 & 63.6 & 27.3 & 72.8 & 72.8 \\
\hline No & 149 & 12.7 & 10.8 & 23.5 & 30.9 \\
\hline $\mathrm{p}$ value & & 0.0003 & 0.127 & 0.0013 & 0.0075 \\
\hline \multicolumn{6}{|l|}{ Femoral stem position } \\
\hline Neutral & 111 & 15.3 & 10.8 & 24.3 & 25.7 \\
\hline Varus & 30 & 13.3 & 20.0 & 33.3 & 35.5 \\
\hline Valgus & 18 & 27.8 & 5.6 & 33.3 & 36.8 \\
\hline $\mathrm{p}$ value & & 0.365 & 0.341 & 0.461 & 0.392 \\
\hline \multicolumn{6}{|c|}{ Acetabular progressive radiolucent lines } \\
\hline Yes & 19 & 21.1 & 15.8 & 36.8 & 42.9 \\
\hline No & 139 & 15.8 & 11.5 & 25.9 & 27.0 \\
\hline $\mathrm{p}$ value & & 0.521 & 0.705 & 0.409 & 0.195 \\
\hline \multicolumn{6}{|l|}{ Femoral bone cement } \\
\hline Low viscosity ${ }^{*}$ & 7 & 57.1 & 14.3 & 71.4 & 71.4 \\
\hline High viscosity $^{\dagger}$ & 130 & 13.9 & 13.1 & 25.4 & 28.2 \\
\hline Low and high viscosity & 10 & 10.0 & 0 & 10.0 & 18.2 \\
\hline $\mathrm{p}$ value & & 0.036 & 0.730 & 0.022 & 0.070 \\
\hline \multicolumn{6}{|l|}{ Surgical team } \\
\hline A & 84 & 15.5 & 13.1 & 28.6 & 30.2 \\
\hline B & 37 & 18.9 & 10.8 & 24.3 & 31.7 \\
\hline Others & 38 & 15.8 & 10.5 & 26.3 & 31.7 \\
\hline$p$ value & & 0.885 & 0.949 & 0.891 & 1.0 \\
\hline \multicolumn{6}{|l|}{ Surgeon } \\
\hline Specialist registrar & 67 & 16.4 & 11.9 & 26.9 & 29.0 \\
\hline Consultant & 92 & 16.3 & 12.0 & 27.2 & 32.3 \\
\hline$p$ value & & 1.0 & 1.0 & 1.0 & 1.0 \\
\hline
\end{tabular}

with the 3M Capital hip (3M Company, St. Paul, Minnesota) has shown, small changes can have a major effect. ${ }^{11}$ The Elite Plus stem evolved by altering the Charnley low friction arthroplasty femoral stem in two stages. Initially, modularity and optional larger femoral heads were introduced into the Charnley Elite system while maintaining an Ortron 90 femoral stem. The Elite Plus system then had additional changes which involved the geometry of the stem. This entailed alteration to the flange, the use of a $135^{\circ}$ neck-shaft angle which increased incrementally with stem size, and the addition of a slot in the tip of the stem and a centraliser.

Survival data for the original Charnley low friction arthroplasty show excellent results, ${ }^{12-17}$ and the Elite Plus appears to perform well in our study. A revision rate of $3.75 \%$ at six years for our inital cohort of 234 THAs is acceptable, based upon the benchmark for an acceptable rate of revision of $0.7 \%$ per annum according to the Swedish Hip Register. ${ }^{18}$ A survival rate at six years of $96.25 \%$ for our series also agrees with the findings of the Swedish Hip Register for the Elite Plus, in which survival was $96.2 \%(93.8 \%$ to $98.5 \%)$ at six years. ${ }^{19}$ Equally, our results are also acceptable when based upon the Oxford hip score. We selected the Oxford hip scoring system since it has been shown to relate accurately to patient satisfaction with the surgical outcome ${ }^{2}$ and also provides data on pain and immobility. ${ }^{20}$ This view is supported by other studies, which recommend the Oxford hip score for the assessment of THA compared with other scores. ${ }^{21}$

However, the use of revision as a standard end-point for survival analysis in THA is a coarse method of assessing prostheses in the medium term. Evidence of radiological 
loosening is a refinement of this end-point and is, perhaps, preferable. When the radiological data were examined in more detail the results were less satisfactory, with $31 \%$ of our THAs showing clear evidence of loosening of a component according to recognised criteria ${ }^{4-6,8,9}$ or having undergone revision for aseptic loosening within six years.

Defining radiological loosening of a cemented implant is difficult. The literature lacks uniformity, although the criteria for loosening of the femoral stem according to Harris et al, ${ }^{4-6}$ or for acetabular loosening according to Hodgkinson et $\mathrm{al}^{8,9}$ are widely accepted. Kobayashi et $\mathrm{al}^{7}$ considered a lucency of $2 \mathrm{~mm}$ which occupies more than one-third of any zone around the stem or migration of the stem of $2 \mathrm{~mm}$, as individual predictors of aseptic loosening over ten years if present on a radiograph at two years. If both features were present at two years, the risk of loosening increased further. The same study also stated that if a lytic lesion of $\geq$ $2 \mathrm{~mm}$ was present at two years, there was a $50 \%$ chance of failure within five years. The criteria of Kobayashi et $\mathrm{al}^{7}$ appear to be more stringent than those proposed by Harris et $\mathrm{al}^{4-6}$ and are, perhaps, more applicable to a medium-term review such as ours. Using refined Kobayashi criteria, $18.2 \%$ of our femoral stems were at risk of failure within five years, even without considering either revisions or acetabular components.

Our results highlight the value of medium-term radiological follow-up after THA. This has been recommended in standard guidelines ${ }^{22}$ and suggests that joint registries should attempt to address the issue. If a registry has no budget to assess patients radiologically, only clinical assessment and revision rates can be used as measures of outcome. We were unable to establish a statistically significant relationship between the clinical and radiological outcome for our patients and this calls into question the sensitivity of a register which does not include radiological data. This view is supported by the failure of hip scores in the Swedish Hip Registry to reflect radiological findings. ${ }^{18,19}$

The reasons for these radiological results of the Elite Plus are not clear. Surgical technique must obviously be considered. To define good surgical technique accurately is difficult, although assessment of immediate post-operative radiographs gives an objective measurement of cement mantles and the position of the implant. A number of radiological features have been noted, which might predict early prosthetic failure. ${ }^{23}$ Most important of these is the grading of cementation by Barrack et al. ${ }^{10}$ Other important predictors of failure are a deficient cement mantle $(<1 \mathrm{~mm}){ }^{24}$ stem-cortex contact and marked $\left(>4^{\circ}\right)$ varus or valgus positioning of the stem. ${ }^{20,21}$ However, it is well recognised that reliable radiological assessment of cementing is difficult and that observer variation is an issue..$^{20,25,26}$

The immediate post-operative radiographs in our series revealed few poorly cemented or poorly positioned implants. The Barrack grading was A or B in $99.4 \%$ of THAs and no statistically significant relationship between failure and grading could be established $(\mathrm{p}=0.221$; Table
IV). However, a defective femoral cement mantle was a statistically significant factor in loosening, supporting the views of other authors. ${ }^{20,21}$ We found that the type of cement was also significant, with Palacos LV performing significantly worse than Palacos R cement, a finding which agrees with other, well-established studies on low-viscosity cements. ${ }^{27,28}$ No significant statistical relationship could be established between varus or valgus placement of the femoral stem and loosening, nor between the surgical team or the grade of surgeon and subsequent loosening. The use of low-viscosity cement and the presence of defective cement mantles could be blamed for the evidence of loosening seen in our series. However, only seven of 159 (4\%) THAs were secured with low-viscosity cement and only $11(6.9 \%)$ had evidence of a defective cement mantle. This does not account for our rate of loosening of $31 \%$.

In conclusion, we have concerns about the long-term survival of the Elite Plus, despite acceptable clinical results and revision rates. The definition of the radiological loosening of prostheses and the use of revision as an end-point in the medium term are also questionable. The lack of any statistical relationship between clinical and radiological outcomes should be considered carefully since, if joint registries are to be successful in identifying early prosthetic failures radiological surveillance must be included.

Although none of the authors has received or will receive benefits for personal or professional use from a commercial party related directly or indirectly to the subject of this article, benefits have been or will be received but will be directed solely to a research fund, foundation, educational institution, or other nonprofit organisation with which one or more of the authors are associated.

\section{References}

1. Norton MR, Yarlagadda R, Anderson GH. Catastrophic failure of the Elite Plus total hip replacement, with a Hylamer acetabulum and Zirconia ceramic femoral head. J Bone Joint Surg [Br] 2002;84-B:631-5.

2. Fitzpatrick R, Morris R, Hajat $\mathbf{S}$, et al. The value of short and simple measures to assess outcomes for patients of total hip replacement surgery. Qual Health Care 2000:9:146-50

3. Johnston RC, Fitzgerald RH Jr, Harris WH, et al. Clinical and radiographic evaluation of total hip replacement: a standard system of terminology for reporting results. J Bone Joint Surg [Am] 1990;72-A:161-8.

4. Harris WH, McCarthy JC Jr, O'Neill DA. Femoral component loosening using contemporary techniques of femoral cement fixation. J Bone Joint Surg [Am] 1982;64-A 1063-7.

5. Madey SM, Callaghan JJ, Olejniczak JP, Goetz DD, Johnston RC. Charnley total hip arthroplasty with use of improved techniques of cementing: the results after a minimum of 15 years follow-up. J Bone Joint Surg [Am] 1997;79-A:53-64.

6. Loudon JR, Charnley J. Subsidence of the femoral prosthesis in total hip replacement in relation to the design of the stem. J Bone Joint Surg [Br] 1980;62-B:450-3.

7. Kobayashi A, Donnelly WJ, Scott G, Freeman MA. Early radiological observations may predict the long-term survival of femoral hip prostheses. J Bone Joint Surg [Br] 1997;79-B:583-9

8. Hodgkinson JP, Shelley P, Wroblewski BM. The correlation between the roentgenographic appearance and operative findings at the bone-cement junction of the socket in Charnley low friction arthroplasties. Clin Orthop 1988;228:105-9.

9. Mulroy RD Jr, Harris WH. The effect of improved cementing techniques on component loosening in total hip replacement: an 11 year radiographic review. J Bone Joint Surg [Br] 1990;72-B:757-60.

10. Barrack RL, Mulroy RD Jr, Harris WH. Improved cementing techniques and femoral component loosening in young patients with hip arthroplasty: a 12-year radiographic review. J Bone Joint Surg [Br] 1992;74-B:385-9.

11. The Royal College of Surgeons of England. An investigation of the performance of the 3M capital hip system. London Royal College of Surgeons, 2001

12. Jacobsson SA, Djerf K, Wahlstrom 0. 20 year results of McKee-Farrar versus Charnley prosthesis. Clin Orthop 1996;329(Suppl):60-8. 
13. Garellick G, Herberts P, Strömberg C, Malchau H. Long-term results of Charnley arthroplasty: a 12-16 year follow-up study. J Arthroplasty 1994;9:333-40.

14. Neumann L, Freund KG, Sorenson KH. Long-term results of Charnley total hip replacement: review of 92 patients at 15 to 20 years. J Bone Joint Surg [Br] 1994; 76-B:245-51.

15. Schulte KR, Callaghan JJ, Kelley SS, Johnston RC. The outcome of Charnley total hip arthroplasty with cement after a minimum 25 year follow up: the results of one surgeon. J Bone Joint Surg [Am] 1993;75-A:961-75.

16. Callaghan JJ, Albright JC, Goetz DD, Olejniczak JP, Johnston RC. Charnley total hip arthroplasty with cement: minimum twenty-five-year follow-up. J Bone Joint Surg [Am] 2000;82-A:487-97.

17. Kavanagh BF, Dewitz MA, Ilstrup DM, Stauffer RN, Coventry MB. Charnley total hip arthroplasty with cement: fifteen-year results. J Bone Joint Surg [Am] 1989; 71-A:1496-503.

18. Malchau H, Herberts $\mathbf{P}$, Soderman $\mathbf{P}$, Oden A. Prognosis of total hip replacement: update and validation of results from the Swedish National Hip Arthroplasty Registry 1979-1998. www.jru.orthop.gu.se (accessed 5/11/04).

19. The Swedish National Hip Arthroplasty registry: annual report 2002. http:// www.jru.orthop.gu.se (accessed 5/11/04).

20. McMurray R, Heaton J, Sloper P, Nettleton S. Measurement of patient perceptions of pain and disability in relation to total hip replacement: the place of the Oxford hip score in mixed methods. Qual Health Care 1999;8:228-33.
21. Ostendorf M, van Stel HF, Buskens E, et al. Patient-reported outcome in total hip replacement: a comparison of five instruments of health status. J Bone Joint Surg $[\mathrm{Br}]$ 2004;86-B:801-8.

22. British Orthopaedic Association. Total hip replacement: a guide to best practice. London: British Orthopaedic Association, 1999.

23. Chambers IR, Fender D, McCaskie AW, Reeves BC, Gregg PJ. Radiological features predictive of aseptic loosening in cemented Charnley femoral stems. J Bone Joint Surg [Br] 2001;83-B:838-42.

24. Mulroy WF, Estok DM, Harris WH. Total hip arthroplasty with use of so-called second-generation cementing technique: a fifteen-year average follow-up study. J Bone Joint Surg [Am] 1995;77-A:1845-52.

25. Harvey EJ, Tanzer M, Bobyn JD. Femoral cement grading in total hip arthroplasty. J Arthroplasty 1998;13:396-401.

26. Kelly AJ, Lee MB, Wong NS, Smith EJ, Learmonth ID. Poor reproducibility in radiographic grading of femoral cementing techniques in total hip arthroplasty. J Arthroplasty 1996;11:525-8.

27. Espehaug B, Fumes O, Havelin LI, Engesaeter LB, Vollset SE. The type of cement and failure of total hip replacements. J Bone Joint Surg [Br]2002;84-B:832-8.

28. Havelin LI, Espehaug B, Vollset SE, Engesaeter LB. The effect of the type of cement on early revision of Charnley total hip prostheses: a review of 8579 primary arthroplasties from the Norwegian Arthroplasty Register. J Bone Joint Surg [Am] 1995;77-A:1543-50 